\title{
6
}

\section{Introduction of Long-Term Care Systems: The Nascent Diffusion of an Emergent Field of Social Policy}

\author{
Johanna Fischer, Alexander Polte, and Meika Sternkopf
}

\section{Introduction $^{1}$}

Old age is a life stage associated with a wide variety of experiences, depending, for instance, on residential location, socioeconomic characteristics, individual life trajectory, health and economic status (LloydSherlock 2010, 231-235). From a welfare policy perspective, it is also

\footnotetext{
${ }^{1}$ This chapter is a product of the research conducted in the Collaborative Research Center "Global Dynamics of Social Policy" at the University of Bremen. The center is funded by the Deutsche Forschungsgemeinschaft (DFG, German Research Foundation)-project number 374666841-SFB 1342.
}

J. Fischer $(\varangle) \cdot$ A. Polte $\cdot$ M. Sternkopf University of Bremen, Bremen, Germany e-mail: johanna.fischer@uni-bremen.de
A. Polte
e-mail: alexander.polte@uni-bremen.de
M. Sternkopf
e-mail: meika.sternkopf@uni-bremen.de 
a period in which particular social risks are likely to occur that calls for mitigation through state intervention. One such risk is long-term care (LTC) dependency, that is, enduring physical and/or mental impairments necessitating assistance with daily living activities. ${ }^{2}$ Unlike acute illness or loss of income in old age, LTC is a so-called "latecomer" of welfare policy which was historically - and in many parts of the world still is-not addressed as a (separate) social policy field (Österle and Rothgang 2010; Ranci and Pavolini 2015; Scheil-Adlung 2015). Nevertheless, we can see that over the past three decades in particular, debates, policy proposals, and reforms dealing with social protection for LTC dependency have picked up in many states as well as in international and transnational exchange. For instance, specific social LTC insurance schemes have been established in countries such as Israel, Germany, Luxembourg, Japan, and South Korea (Schmidt 2005; Companje 2014, 102; Maags 2020). In Latin America, Uruguay recently introduced a National System of Care, and similar proposals are being discussed elsewhere in the region (Matus-Lopez and Cid Pedraza 2016; Esquivel 2017). Meanwhile, LTC is also increasingly addressed on the international level, for example in different forums and entities of the United Nations (UN) (Second World Assembly on Ageing 2002; WHO 2015, 2017).

In the present chapter, we aim to investigate what factors-international as well as domestic - have so far contributed to the introduction of LTC systems under public responsibility for the elderly worldwide. That is, our explanandum is the point in time at which states first adopted statutory entitlements concerning social protection for LTC for (at least) the old-age population. To this end, we employ data on introduction points taken from the novel Historical Long-Term Care Systems Dataset (Fischer and Sternkopf 2021). In the next section, based on theoretical considerations borrowed from welfare state research and literature focusing on LTC policy, we specify several hypotheses on the role of horizontal and vertical diffusion channels and countries' national constellations in the

\footnotetext{
${ }^{2}$ In general, care dependency can occur at any age, e.g. due to a disability causing loss of functional capacity. However, there is a strong (statistical) association between age and LTC dependency, making old age the period of life with the highest risk of needing LTC (WHO 2015; Colombo et al. 2011).
} 
introduction of LTC systems. Subsequently, we outline the operationalization of our dependent and independent variables. We then move on to conduct the empirical analysis using a discrete-time logistic hazard model, presenting the method, results, and limitations. In the final part, we discuss the findings and conclude.

\section{Theory and Hypotheses}

Generally, there is a lack of (cross-country) explanatory analysis on the introduction of social protection schemes for LTC which makes it difficult to build on previous theoretical specifications and results for formulating hypotheses. However, some insights for explaining the introduction of LTC systems can be drawn from assumptions and observations in publications on LTC in general and in particular from the body of (case) studies exploring LTC policy reform and design (e.g., Campbell et al. 2009; Theobald and Kern 2011; Esquivel 2017). Furthermore, the theory strands used to analyze welfare policies in general (see e.g., Schmitt et al. 2015) seem to be a fruitful starting point for theorizing about the policy field of LTC (cf. Leitner 2013, 51-52). Consequently, we use these existing bodies of literature to structure and underpin our subsequent theoretical discussion. In line with the focus of this edited volume, we start with interdependencies and then move on to identify relevant domestic factors.

\section{International Interdependencies}

Moving beyond "methodological nationalism," the study of policy diffusion and policy transfer (see e.g., Marsh and Sharman 2009; Obinger et al. 2013) has highlighted the relevance of transnational and international interdependencies for countries' (social) policy decisions. The concept of diffusion assumes "contagion" between different entities. Consequently, in comparative policy research, diffusion describes a process "in which policies in one unit are influenced by concepts, proposals, policies or ideas from another unit" and can occur in different 
constellations: horizontally from country to country, vertically from international organization $(\mathrm{IO})^{3}$ to country or vice versa, or in the form of imperial diffusion (Kuhlmann et al. 2020, 82, 85). As regards the diffusion of LTC system introduction, diffusion both between countries and from IOs to countries seems plausible. In the following, we outline both.

As described in the introductory chapter (Mossig et al., in this volume), multiple types of ties may drive diffusion of social policies between countries: geographical, cultural, and economic proximity and colonial ties (cf. Elkins and Simmons 2005; Schmitt and Obinger 2013). So which "contagion channels" do we expect to play a role for the horizontal diffusion of LTC systems in particular? While "macro" diffusion patterns of LTC schemes have not been analyzed so far, there are studies on the role of LTC policy transfer in a small number of European and East Asian countries that provide clues on relevant ties. This body of literature points to the role of relationships established through similar welfare state institutions (Maags 2020, 13; Campbell et al. 2009) as well as "geographical and cultural proximity" (Theobald and Kern 2011, 334). In general, it seems plausible that spatial proximity fosters the spread of ideas on establishing social protection for LTC dependency. From LTC research, at least two groups of geographically close countries with similar LTC models and evidence of international exchanges on the topic come to mind: the Scandinavian countries with their universal public service model (Sipilä et al. 2000), and the spread of social LTC insurance in East Asia (Maags 2020). Therefore, it may also be the case that countries learn from a geographically close "reference group" (Elkins and Simmons 2005, 45) with regard to the introduction of an LTC system, which leads us to investigate the following hypothesis: Close geographical proximity to countries with an established LTC system increases the likelihood of introduction of LTC systems (H1a, geographic diffusion hypothesis).

Furthermore, we assume that cultural similarity is especially interesting in the policy field of LTC (cf. Pfau-Effinger 2019, 222). For instance,

\footnotetext{
3We use the term "international organization" in a broad sense, subsuming both global as well as regional associations of states and including supranational organizations such as the European Union.
} 
in their analysis of LTC policy transfer in several European countries, Theobald and Kern $(2011,334)$ point to the shared cultural and historical heritage of Austria, the Czech Republic, and the Italian region of South Tyrol, arguing that this may be one of the reasons why the latter two have oriented themselves to the Austrian LTC system. A particular aspect of culture that seems to be relevant with regard to the field of LTC is family values, that is, "cultural values and notions with respect to the structure of the family and the gender division of labour" (Pfau-Effinger 2005, 328). For instance, shared norms about the role of informal care provision by women could foster countries' exchange on the need for and form of social protection for LTC. We test the relevance of shared cultural norms with the following hypothesis: Close cultural similarity to countries with an established LTC system increases the likelihood of diffusion of LTC systems (H1b, cultural diffusion hypothesis).

LTC is a comparably recent field of social policy which has developed mostly since the dissolution of colonial empires. Moreover, at the time of publication relatively few LTC schemes have been introduced in the Global South (see Fig. 6.2), which suggests that there is no strong theoretical correlation between the direct role of colonial ties and the establishment of LTC systems. However, shared colonial heritage has facilitated the development of similar national (welfare) institutions (Schmitt 2015), which, in turn, could encourage later exchanges on finding a fitting "policy solution" for LTC. For example, there is evidence that countries with preexisting social insurance models such as Japan or South Korea sought advice from countries with similar institutions and experiences for modeling their LTC systems (Campbell et al. 2009; Maags 2020). For this reason, we explore the relevance of colonial ties as a third channel for horizontal policy diffusion: Colonial relations with countries with an established LTC system increases the likelihood of diffusion of LTC systems (H1c, colonial diffusion hypothesis).

Aging and LTC are not only discussed in and among countries, but also by IOs. Organizations such as the European Union (EU), the Organization of Economic Co-operation and Development (OECD), the World Bank or the World Health Organization (WHO) address these issues through recommendations, comparative studies, or monitoring systems. While the topic has recently also gained importance among 
globally active IOs as well (see e.g., WHO 2015; UN DESA 2016), organizations of the Global North have been especially active in the field since the 1990s. For instance, the OECD published its first report on the situation of the elderly in the mid-1990s (Hennessy 1994) and has since established a comprehensive LTC database. In the EU, which, as a supranational organization, can exercise a strong influence on its member states, calls for national policies on LTC in the face of an aging society came on the agenda as early as 1993 (Pacolet et al. 1999). At the end of the "European Year of Older People and Solidarity between Generations" in 1993, the Council of Ministers published a declaration calling on Member States to initiate regulations in the field of LTC (Council of the European Union 1993). In the same year, the Commission published a report comparing health care and social protection schemes in European countries (Commission of the European Communities 1993; Hervey and Vanhercke 2010). Thus, EU membership since 1993 may have been a channel for vertical LTC policy diffusion. Not only the current members, moreover, but also applicants may have been influenced by the EU's agenda-setting, particularly in the 1990s, at a time when some of the Central and Eastern European countries aspired to membership in the EU and were therefore perhaps more eager to reform their welfare systems (Mattli and Plümper 2002; Theobald and Kern 2011). Thus, our hypothesis on vertical diffusion is the following: (Prospective) Membership in the European Union after 1993 increases the likelihood of introducing an LTC system (H2, EU diffusion hypothesis).

\section{National Constellations}

As regards domestic explanatory factors, (at least) three theoretical strands are classically differentiated in welfare (state) studies to account for the emergence, change, and variation of social policies (see e.g., Huber and Stephens 2001, 15; Pierson 1996; Schmitt et al. 2015, 510). These are functionalist or socio-economic theories that stress the relevance of economic, technical, and societal change in driving social policy introduction, actor and interest-based theories that focus on the influence of political and societal groups and coalitions, and institutionalist theories 
which postulate the influence of existing (political) rules, structures and norms on social policy development. In this section, we turn to these theoretical schools and specify four hypotheses on the role of national constellations in the introduction of LTC systems.

Many publications dealing with LTC in different parts of the world frame the need for (political) activity and research in the field in terms of growing problem pressure (e.g., Österle et al. 2011; Feng 2019, 291-293; Colombo et al. 2011, 62-70). Two aspects are frequently cited. On the one hand, there is a (projected) increase in care dependency prevalence ${ }^{4}$ in conjunction with demographic aging of societies; on the other hand, a decrease in informal (familial) care provision due to higher female labor market participation and more dispersed family structures is discernible. This narrative is clearly embedded in functionalist theory. Accordingly, economic and technical change leads to changing demographic and societal structures which create new social issues and risks-in this case, a "care gap"-which call for mitigation from the (welfare) state (Obinger 2019; Bonoli 2007). To examine whether states act in line with this modernization logic, we formulate the following hypothesis: The higher the prevalence of LTC dependency in a country, the higher the likelihood of LTC system introduction (H3a, problem pressure hypothesis).

Besides problem pressure, functionalist theory also stresses the importance of economic resources for social policy adoption and expansion: With growing wealth, countries have more means available for welfare spending (Obinger 2019; Leitner 2013, 41). While up to now this assumption has yielded ambiguous results for different social policies and time periods (see e.g., Schmitt et al. 2015; Jensen 2011), it has to our knowledge never been tested with regard to LTC specifically. We therefore investigate whether the following hypothesis holds for LTC policy: The more economically wealthy a country is, the higher is the likelihood of LTC system introduction (H3b, economic wealth hypothesis).

With a view to the role of actors and interests, a classical explanation for the expansion of welfare transfer programs (e.g., old-age pensions, unemployment benefits) in the Global North stresses the importance of different classes' power resources, in particular the influence of strong

\footnotetext{
${ }^{4} \mathrm{LTC}$ prevalence describes the share of care dependent persons within the population.
} 
left-wing and social democratic parties and trade unions (Pierson 1996, 150; Orloff 2005). However, this seems to be less the case for social and health care services (e.g., Leitner 2013; Jensen 2011; Bonoli and Reber 2010). Consequently, in the policy field of LTC, it is more plausible to consider the influence of other actors and ideologies. For instance, several case studies on LTC policy reform point to the relevance of women's organizations and movements (e.g., Peng 2005; Esquivel 2017). As (informal) care provision is feminized to a large degree (WHO 2015, 130; Österle and Rothgang 2010), women in particular are likely to be interested in relief from or support with unpaid care provision-either by remuneration and recognition of informal provision or by strengthening the formal LTC sector. Therefore, the extent of women's political opportunities and participation within a society stands out as a potential factor influencing the introduction of an LTC system. In terms of actor-based theories, we therefore explore the following hypothesis: The more that women in a country are politically empowered, the higher is the likelihood of LTC system introduction (H3c, women empowerment hypothesis).

The configuration of political institutions and regimes can generally also influence welfare policy (Pierson 1996, 152). One assumption regarding the role of a country's political regime type is that democracies tend to expand social policy benefits more than autocratic states because freedom of association and elections offer the population possibilities to successfully press for social protection schemes (Haggard and Kaufman 2009, 13-14). In the case of LTC, these could be groups directly affected by (the risk of) care dependency, but also those indirectly affected, such as family caregivers and people working in the formal care sector. Although the connection between regime type and the size of the welfare state is not straightforward (Schmidt 2019; Schmitt et al. 2015, 511), we explore the following hypothesis: The more democratic a country is, the higher is the likelihood of LTC system introduction (H3d, regime type hypothesis). 


\section{Operationalization and Data}

After the theoretical framework has been outlined above, we now turn to the empirical analysis. This section firstly outlines the dependent variable, i.e., LTC system introduction, and, secondly, specifies the operationalization and data sources used to measure our independent variables.

\section{Dependent Variable: Measuring the Introduction of LTC Systems}

Country-comparative data on the recently developed, complex policy field of LTC is scarce, in particular with a view to information on the historical development of LTC schemes. ${ }^{5}$ Up until very recently, there was no data available on the emergence of LTC systems (or similar concepts) across countries. This paper therefore uses a novel dataset generated in the CRC project A04 Global Developments in Health Care Systems and Long-term Care as a New Social Risk, the Historical LongTerm Care Systems Dataset (HLTCS) (Fischer and Sternkopf 2021). This dataset covers all countries globally with more than 500,000 inhabitants in 2017 and contains, among others, two different measures for the existence and introduction dates of LTC systems under public responsibility. Thus, on the one hand, the introduction of an LTC system (type A) can be defined (i) as the first point in time when nationwide legislation is adopted, (ii) this legislation establishes entitlements to LTC benefits, and (iii) the elements of the LTC system are integrated to some extent (De Carvalho and Fischer 2020, 12-15). ${ }^{6}$ On the other hand, when applying a stricter understanding, an LTC system is only defined as

\footnotetext{
5There are some exceptions, most notably: since 2004 yearly updated comparative tables presenting a structured description of countries' LTC schemes in the wider European area by the Mutual Information System on Social Protection (MISSOC) and the Mutual Information System on Social Protection of the Council of Europe (MISSCEO), and a collection of laws on LTC for ten European countries by the Social Policy and Law Shared Database (SPLASH).

${ }^{6}$ The latter point is operationalized as the existence of an institution or set of institutions explicitly responsible for LTC.
} 
having been introduced if the former criteria are fulfilled and in addition, in acknowledgment of LTC dependency as a distinct social risk (type B), LTC is institutionally treated as a social policy field of its own. Overall, while the development of such distinct LTC systems is often regarded as a remarkable event in the social policy landscape of a country, type B systems are globally still extremely rare, totaling 15 in 2010 and 18 by 2020 (see Fig. 6.1, dark red dotted line). By contrast, LTC systems of the former definition may often represent rather incipient and hidden developments, but are nevertheless an important first step toward social protection for LTC. Therefore, in this chapter, we analyze the introduction of the more widespread type A LTC systems, using as our dependent variable the adoption year of the foundational law which introduces for the first time statutory benefits relating to social protection for LTC for (at least) the old-age population. In the remainder of this section, we briefly describe the distribution of this variable over time, which is also visualized in the (cumulative) adoption graph in Fig. 6.1.

As shown by the light red lines in Fig. 6.1, LTC systems started to emerge from the mid-twentieth century onwards. The first country to introduce an LTC system was the United Kingdom with the adoption of

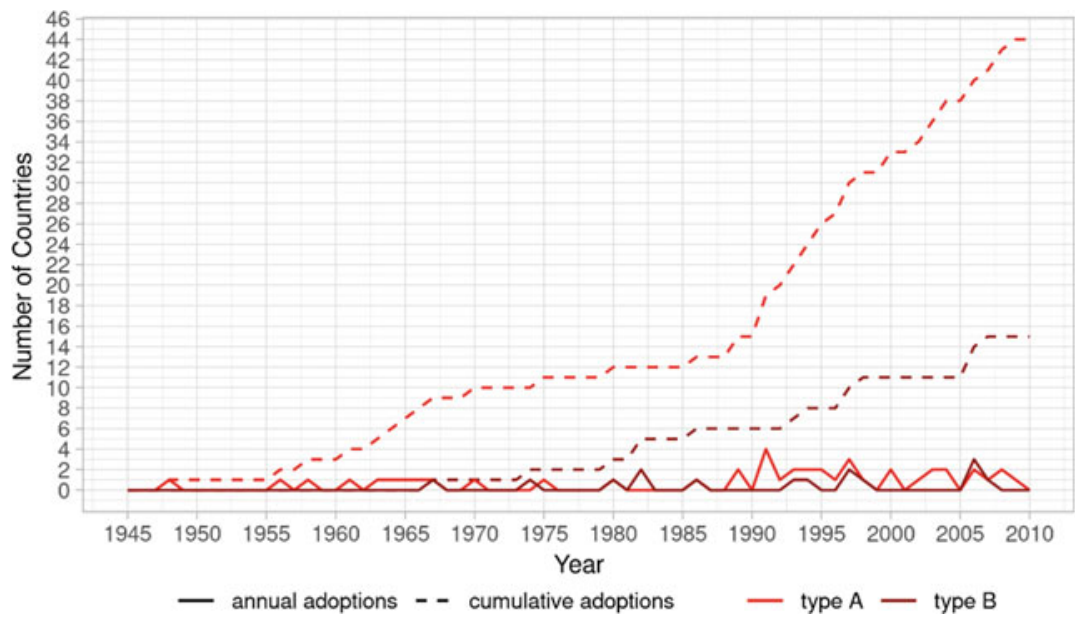

Fig. 6.1 Adoption of LTC systems (type A and B) worldwide, until 2010 (Source Own representation, data taken from HLTCS [version 31.01.2020]) 


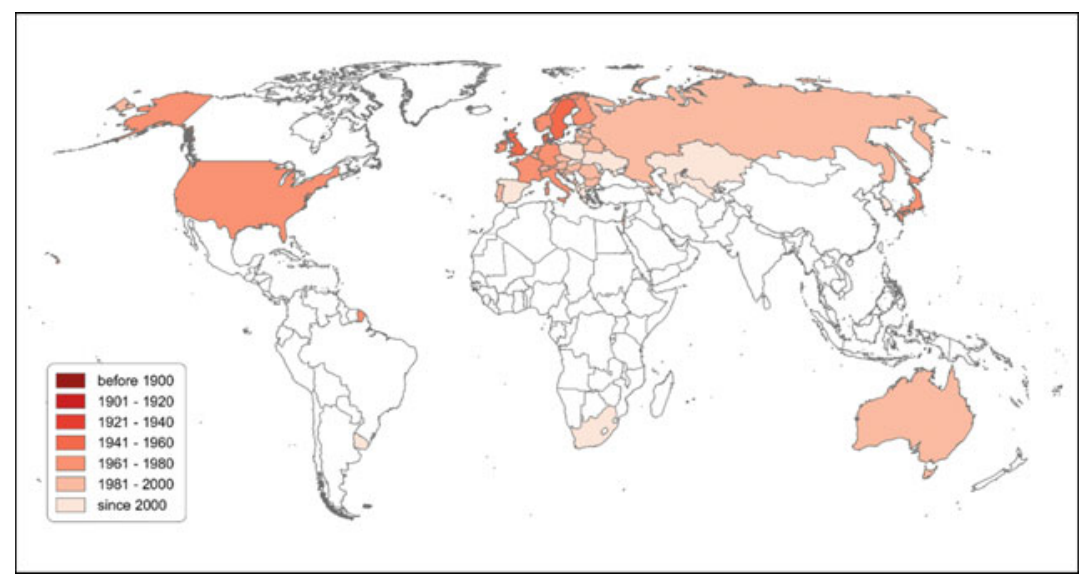

Fig. 6.2 World map of LTC system introductions (Source Data taken from HLTCS [version 31.01.2020]; Data missing for the following countries: Algeria, Bahrain, Bangladesh, Iraq, Jordan, Kuwait, Lebanon, Malaysia, Moldova, Morocco, Nepal, New Zealand, North Korea, Oman, Philippines, Qatar, Tanzania, Tunisia, Uganda, Zimbabwe)

the National Assistance Act in 1948. In the subsequent decades, the adoption process was rather slow and mostly took place in Europe. The first Asian country to introduce an LTC system was Japan in 1963, closely followed by the United States in 1965 as the first on the American continent (see Fig. 6.2). Introduction picked up in the 1990s, as indicated by the steep light red dotted curve in Fig. 6.1. As many as 16 countries, mostly Eastern European states some of which were newly (re-) established shortly beforehand, adopted a novel LTC system from 1991 until 1998. In the 2000s, the regional diversity of countries increased to some extent, with introductions in several Asian countries as well as in South Africa. Overall, less than a third of all countries worldwide had introduced an LTC system by 2018, indicating that the diffusion process of this social policy is still at an early stage. As shown on the map in Fig. 6.2, the majority of system introductions until today is clearly centered on Europe. 


\section{Independent Variables}

Following our theoretical framework, the independent variables can be divided into two groups: international interdependencies $(\mathrm{H} 1, \mathrm{H} 2)$ and national constellations (H3). We operationalize horizontal international interdependencies by calculating network exposure values (Valente 1995; 2005) for three potentially relevant horizontal networks: geographic proximity (H1a), cultural similarity $(\mathrm{H} 1 \mathrm{~b})$, and colonial legacy $(\mathrm{H} 1 \mathrm{c})$. Network exposure is defined by the proportion of a country's neighbors which already adopted an LTC system. In this regard, all countries to which the focal state is linked via a certain network tie (e.g., colonial legacy) count as neighbors. It is also possible to account for the weights of network ties. An in-depth explanation and discussion of network exposure and its calculation are provided in Chapter 1 of this volume (Mossig et al. 2021, in this volume).

To operationalize vertical policy diffusion from the EU to the national level (H2), we created a dataset that indicates the point in time at which a country applied for EU membership and when it became an EU member state. Based on this data, we identify for each year those countries that are members of the EU or official EU applicants. In the following, we will refer to this country set as the extended EU group. Starting with 1993, which marks the beginning of EU engagement in LTC (see theory section), the variable is set to " 1 " if a country is part of the extended EU group. For the years prior to 1993 and for non-group members it is coded "0."

We now turn to the operationalization of our hypotheses on national constellations. Measuring LTC dependency as specified in the problem pressure hypothesis $(\mathrm{H} 3 \mathrm{a})$ is challenging, as there is no data source providing information about the prevalence of LTC dependency that covers countries worldwide or historically. As research clearly indicates that LTC dependency is strongly associated with (very) old age (see e.g., WHO 2015, 65-69; Colombo et al. 2011, 40-43), we use the share of old-age population as a proxy measure. While statistics on the Global North indicate that LTC prevalence increases significantly at the age 
of 80 years and above (Colombo et al. 2011, 40-43), data for countries in the Global South, where the average life expectancy is lower, indicates limitations in activities of daily living even for the "younger elderly" (WHO 2015, 68). As a compromise, we use the share of population aged 75 years and older to operationalize LTC dependency. To do so, we employ data provided by UN DESA (2019). It includes information about the share of population aged $75+$ years in percent at five-year intervals and covers the period from 1950 until 2020. To cope with missing values, we use linear interpolation to impute data for unobserved country years.

For the wealth hypothesis $(\mathrm{H} 3 \mathrm{~b})$, we use the gross domestic product (GDP) per capita in units of 10,000 US\$ to operationalize countries' economic power. Since this variable is extensively described in Chapter 1 (Mossig et al., in this volume), we forego redescribing the data here.

To operationalize the women empowerment hypothesis $(\mathrm{H} 3 \mathrm{c})$ the women's political empowerment index (Sundström et al. 2015) is used, which is obtained from the Varieties of Democracy (V-Dem) dataset (Coppedge et al. 2020). The index is an aggregate of three subindiceswomen's civil liberties index, women's civil society participation index, and the women's political participation index-and ranges from " 0 ," indicating a low level of political empowerment of women, to " 1 ," indicating high political empowerment. Missing values have been filled with linearly interpolated values.

Finally, for the regime type hypothesis (H3d), we use the level of democratization taken from V-Dem (Lührmann et al. 2018; Coppedge et al. 2020) and described in Chapter 1. Values range from "0"closed autocracy - to "9"-liberal democracy_and missing data has been interpolated linearly (see Mossig et al., in this volume). Now that our measurements have been specified, we move to the presentation of the employed method, results, and limitations of our analysis. 


\section{Explaining the Introduction of LTC Systems}

\section{Method}

In line with the methodological approach followed in this volume, we use discrete-time logistic hazard models to estimate the influence of the independent variables on the hazard ratio of LTC system introduction (cf. Windzio 2013; Valente 1995; 2005). Due to missing data in at least one of the independent variables, our models do not include the following countries from the original country sample of this volume: Bhutan, East Timor, Fiji, Guyana, Papua New Guinea, Solomon Islands, Somalia, South Sudan, and Suriname. Thus, the models cover observations from $N=154$ countries during the time period 1945-2010. We selected 1945 as the starting point for several reasons. Firstly, it does not exclude any LTC system introductions (the first is in 1948), and, secondly, data for some of our independent variables are only available from the 1940s/50s onwards. Under these circumstances, we deem it reasonable to pick a historic turning point — the end of World War II-as the starting point for our analysis.

We defined two time intervals for the piece-wise constant rate function of logistic hazard models - one period from 1945 to 1977, and one from 1978 to 2010 . The choice is motivated by the aim of creating intervals of similar length on the one hand, and by reducing the amount of control variables on the other. We consider this to be a reasonable approach, since the total number of LTC systems introduced by the end of the observation period in 2010 is still very small $(n=43)$ compared to the sample size $(N=154)$. Countries which did not introduce an LTC system until 2010 were treated as right-censored cases.

To facilitate a straightforward interpretation of the model results we also conducted certain data transformations. Firstly, the women's political empowerment index has been converted to a percentage scale. Secondly, the variable values of "share of population 75+" and "GDP per capita" have been centered, by subtracting the grand mean from each. Since centering only shifts the values proportionally, the procedure does not affect the model results, while it may improve the models' 
readability (Aiken and West 1991). As proposed in the introductory chapter, we addressed the issue with non-independent observations by using cluster-robust standard errors (Zeileis et al. 2020).

\section{Results}

Table 6.1 shows the predicted hazard ratios of LTC system introduction. While Model 1 contains the full set of independent variables introduced above, Model 2 additionally includes an interaction term for the centered variables "share of population 75+" and "GDP per capita."

Of the three network diffusion variables, only network exposure by geographical proximity shows a significant and positive effect in both models. This supports the geographic diffusion hypothesis (H1a), showing that geographic proximity promotes the diffusion of ideas and policy innovations. On a substantial level this result reflects the large cluster of LTC systems in Europe, where the first LTC systems were developed.

Table 6.1 Discrete-time logistic hazard model of LTC system introduction ( $N=$ 154)

\begin{tabular}{|c|c|c|}
\hline & \multicolumn{2}{|c|}{$\begin{array}{l}\text { Dependend variable: Introduction } \\
\text { Year of Long-Term Care Systems }\end{array}$} \\
\hline & Model 1 & Model 2 \\
\hline 1945-1977 & $0.0000^{* * *}(1.20)$ & $0.0000^{* * *}(1.36)$ \\
\hline $1978-2010$ & $0.0000^{* * *}(1.29)$ & $0.0000^{* * *}(1.45)$ \\
\hline Network exposure: proximity & $203.80^{* * *}(1.28)$ & $117.12^{* * *}(1.27)$ \\
\hline Network exposure: culture & $0.05(2.21)$ & $0.10(2.20)$ \\
\hline Network exposure: colonies & $1.00(0.46)$ & $0.98(0.43)$ \\
\hline Extended EU group & $1.23(0.59)$ & $1.11(0.59)$ \\
\hline Share of population $75+$ & $1.30(0.18)$ & $1.52^{*}(0.17)$ \\
\hline GDP per capita & $1.19(0.22)$ & $1.15(0.12)$ \\
\hline Women pol. empowerment index & $1.06^{* \star}(0.02)$ & $1.06^{* *}(0.02)$ \\
\hline Democratization & $1.21^{*}(0.09)$ & $1.24^{*}(0.08)$ \\
\hline Interaction: GDP*Pop 75+ & & $0.86^{*}(0.06)$ \\
\hline Observations & 9080 & 9080 \\
\hline Log Likelihood & -195.104 & -192.451 \\
\hline Akaike Inf. Crit & 410.208 & 406.903 \\
\hline McFadden $R^{2}$ & 0.285 & 0.295 \\
\hline
\end{tabular}

Note: ${ }^{+} p<0.1 ;{ }^{*} p<0.05 ;{ }^{* *} p<0.01 ;{ }^{* *} p<0.001$ 
The culture diffusion hypothesis (H1b) is not supported by our models and must be rejected under the conditions of Model 1 and Model 2, because the coefficients are not significant. Similarly, the lack of statistical significance of network exposure by colonial relationships is not in line with the colonial diffusion hypothesis (H1c). While the rejection of the colonial diffusion hypothesis is understandable as the theory section has already highlighted the weak connection between LTC policy and colonial empires, it is indeed surprising that we find no evidence for diffusion by cultural similarity in our analysis.

Regarding the $E U$ diffusion hypothesis, both models yield unexpected results. The effects are not statistically significant, indicating that the EU agenda-setting on LTC policy since 1993 did not influence the risk of LTC system introduction among EU members and applicants. This is a puzzling result, as it implies that the role of the EU in the field of LTC is less influential than in other social policy fields described in the literature, such as pensions or gender equality (Cerami 2008; Guillén and Palier 2004; O’Connor 2005).

Model 1 shows a positive but not statistically significant effect for the problem pressure ( $\mathrm{H} 3 \mathrm{a}$ ) variable "share of population $75+$. " This result indicates that countries do not generally tend to introduce LTC systems earlier as the prevalence of LTC dependency increases, and therefore $\mathrm{H} 3 \mathrm{a}$ is rejected by Model 1. Similarly, "GDP per capita" shows no significant correlation to the adoption risk in Model 1. This finding contradicts the economic wealth hypothesis (H3b), which assumes that economic affluence increases the likelihood of introducing an LTC system. To investigate this result further, we discuss the effects of the interaction term included in Model 2 at the end of this section.

The coefficients of the women's political empowerment index are significantly positive in both models. Since the variables represent the original index on a percentage scale, the hazard of introducing an LTC system increases by $6 \%$ for each additional percent of the index. Recapturing the $10 \%$ interval of the original index, an increase by one level statistically results in a $60 \%$ higher risk of LTC system introduction. Thus, the model results support the women empowerment hypothesis $(H 3 c)$. Similarly, both models predict a significant positive effect of the level of democratization. Since the effects in both models point in the 
same direction, we can draw from them at least weak empirical support for the regime type hypothesis ( $H 3 d$ ).

In Model 2, we have added an interaction term for economic wealth and problem pressure, because we expected that the influence of problem pressure could be of greater relevance if a country is comparably rich and can better afford to introduce LTC benefits. Furthermore, we were surprised by the absent statistical significance of problem pressure and economic wealth in Model 1. Consequently, the additional interaction hypothesis reads: The higher the economic wealth, the stronger the effect of high prevalence of LTC dependency on the risk of LTC system adoption (IH).

In Model 2 the effect of "share of population 75+" increases compared to Model 1 and becomes significant $(p<0.05)$. Thus, in countries of average economic wealth an increase of the "share of population 75+" by one percent increases the odds for LTC system introduction by $52 \%$. The GDP per capita coefficient, however, remains insignificant and thus indicates that economic wealth has no influence on the risk of adoption for countries with average problem pressure.

Finally, the interaction term itself shows a significant negative coefficient. Figure 6.3 shows the predicted probabilities of LTC system adoption related to the share of population aged 75 and older, while the lines represent the effect difference among countries of average (blue), low (red), and high (green) economic wealth. The latter two indicate values which are one standard deviation below and above the mean, respectively. As shown in Fig. 6.3, the overall positive effect of problem pressure on the adoption risk is dampened as economic wealth increases. However, Fig. 6.3 also shows that this dampening effect almost only applies to countries with relatively high problem pressure $(1.02 \%$ above average and higher).

Our interaction hypothesis therefore has to be rejected. The positive effect of high problem pressure on the introduction of LTC systems does not increase with economic wealth. One possible explanation for this surprising finding could be that elderly people in richer countries may have better opportunities to make provisions for future LTC dependency during their working life. They also might receive higher old-age 


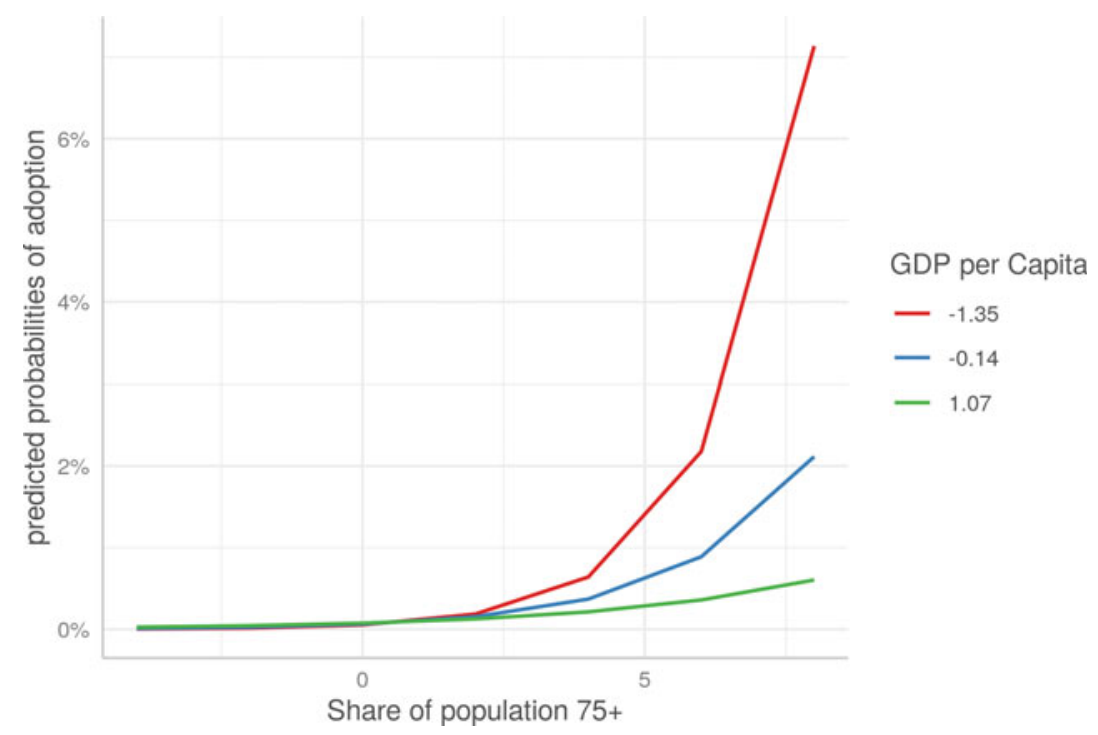

Fig. 6.3 Interaction effects

pensions allowing them to pay for LTC services more easily. Consequently, with high problem pressure, the necessity for social protection for LTC (especially for the poorest population strata) could be even more pressing in less wealthy countries.

\section{Limitations}

The analysis faces several limitations. As already mentioned, LTC is a relatively nascent social policy field, and LTC dependency as a new social risk only recently became more salient in many societies. The data on the introduction of LTC systems presented in this study underlines this fact and shows that the global diffusion of LTC systems is still at an early stage. Only 43 of the 154 countries incorporated in our model have been classified as adopters of LTC systems by 2010. Five further countries $^{7}$ introduced an LTC system after the end of our observation period

${ }^{7}$ Azerbaijan (2014), Uruguay (2015), Uzbekistan (2015), Albania (2016), Greece (2016). 
and were treated as right-censored in our model. Furthermore, the introduction data was missing for 20 countries, ${ }^{8}$ which we also treated as cases without an LTC system, because initial country screenings suggest that they did not introduce an LTC system until 2010. Both the early stage of diffusion and data uncertainty restrict the present analysis. As mentioned above, these concerns also led us to use only two steps for the piece-wise constant rate function. We also refrained from including trade network exposure and the additional trade existence control variable used throughout the edited volume, because there are neither substantial theoretical arguments for the relevance of economic interdependencies in LTC, nor did it show any significant empirical result when included in the model. However, for the sake of completeness, Tables 6.2 and 6.3 in the appendix show model results which include trade exposure effects as well.

Besides the measurement problems associated with a lack of appropriate data discussed for some explanatory variables-especially problem pressure-above, there are also limitations concerning the operationalization of the dependent variable. As discussed in the section on operationalization and data, type-A LTC systems constitute rather incipient forms of social protection for LTC which are sometimes not recognized as such (at the time) and often establish only rudimentary entitlements which may in fact be irrelevant to large parts of the population. However, political activism, the role of economic means for funding, and the diffusion of ideas may be stronger with regard to "big bang" events like the introduction of distinct LTC systems (type B). For instance, the insights on LTC policy transfer provided by existing case studies (see theory section) all refer to the adoption of distinct LTC systems since the 1990s. Therefore, it might be fruitful to also further investigate the establishment of distinct LTC systems, even if their small number makes a (statistical) analysis currently difficult.

\footnotetext{
${ }^{8}$ Algeria, Bahrain, Bangladesh, Iraq, Jordan, Kuwait, Lebanon, Malaysia, Moldova, Morocco, Nepal, New Zealand, North Korea, Oman, Philippines, Qatar, Tanzania, Tunisia, Uganda, Zimbabwe.
} 


\section{Conclusion}

Our analysis has identified several factors which advance the introduction of LTC systems. These are, most notably, diffusion by means of geographical proximity, high political empowerment of women and, to some extent, a high level of democratization. In general, it is surprising that both of our strongest LTC-specific hypotheses on international interdependencies, that is horizontal diffusion through cultural similarity and vertical diffusion within the extended EU group, have to be rejected. One explanation for the absent influence of the $\mathrm{EU}$ on the introduction of LTC systems may be that LTC policy in particular is regarded as a national matter by the member states, which is justified by the low legitimacy of the EU in social policy issues. Moreover, many member states had already introduced LTC policies before 1993, which in turn allows the reverse assumption that member states influence the social policy agenda of the EU institutions. Moreover, as agenda setting only started in the 1990s, it is possible that the EU influences the further development toward distinct LTC systems rather than the first legal provisions in the field.

On a more general note, when analyzing the results on the different "contagion channels," it is important to bear in mind that LTC system diffusion is still an ongoing, accelerating process. Consequently, our current model provides a description of the early phase of diffusion, and not a generalizable explanation of the global diffusion process as a whole. The same methodological approach may identify other factors or assign different relevance to them as more countries introduce LTC systems subsequent to 2010. Recapturing the self-referential/endogenous dynamic of network diffusion processes, this might even lead to the identification of further diffusion channels, which become more relevant as exposure thresholds mediated by their increase.

With regard to national constellations, our findings provide very limited support for the functionalist explanations on economic wealth and problem pressure. The lack of statistical evidence of the problem pressure hypothesis is an unexpected result in view of the fact that the body of international literature on LTC continuously stresses the relevance of aging while urging governments to introduce social protection 
schemes for LTC. Nevertheless, as the result of the interaction model shows, a high share of elderly people seems to matter in countries with low to average wealth. Although not explicitly hypothesized in this chapter, one can regard this finding as partly supporting the functionalist explanation relying on problem pressure. Unfortunately, due to a lack of data, we were unable to test the flip side of the problem pressure hypothesis relating to the availability of informal care as a functional equivalent to public LTC systems. Wealth itself does not seem to be a major driving force behind the introduction of LTC systems introduction. However, it still appears to be of importance as the influence of other factors, especially problem pressure, depends on economic affluence.

Our actor-centered assumption about the political role of women is confirmed. This result shows that women's political participation is not only important for the establishment of childcare policies (e.g., Bonoli and Reber 2010) but also with regard to elder care, which has until now been less examined. However, it is not completely clear what the underlying mechanism of this positive effect is. On the one hand, as specified in the theory section, it could be directly related to women's political participation and activism. On the other hand, a general culture of gender equality associated with high political empowerment of women could also be behind this result. Furthermore, as regards one other common hypothesis of welfare theory, namely, the role of the political regime type, our findings also provide statistical evidence for the positive influence of democratization. In fact, there have been very few introductions in (strongly) autocratic regimes-only eight countries with an LTC system, mostly former members of the Soviet Union and Yugoslavia, display a regime type score below five at the time of introduction.

Overall, the present chapter provides - to our knowledge-the first cross-country statistical analysis that explores why countries introduce social protection for LTC dependency. By including variables which measure both horizontal as well as vertical diffusion processes, we also go beyond the explanatory factors rooted in "methodological nationalism" which has often accompanied analyses of social policy development (cf. Obinger et al. 2013). Due to the fact that LTC is only recently evolving as a (distinct) policy, the field can provide fruitful ground for studying both international interdependencies as well as sectoral path 
dependencies, as we can currently observe the spread of the policies. Moreover, information and data are more readily available for this recent historical period than for the beginning of the twentieth century. We therefore conclude that the global diffusion of LTC systems will remain a worthwhile field for future study.

\section{Appendix}

See Tables 6.2 and 6.3.

Table 6.2 Results-additive diffusion models

\begin{tabular}{|c|c|c|c|c|}
\hline & (1) & (2) & (3) & (4) \\
\hline 1945-1977 & $0.0001^{* * *}$ & $0.0000^{* * *}$ & $0.00^{* * *}$ & $0.00^{* * *}$ \\
\hline 1978-2010 & $0.0000^{* * *}$ & $0.0000^{\star * *}$ & $0.00^{\star * *}$ & $0.00^{\star \star \star}$ \\
\hline $\begin{array}{l}\text { Women pol. } \\
\text { empowerment } \\
\text { index }\end{array}$ & $1.05^{* *}$ & $1.06^{* *}$ & $1.05^{* *}$ & $1.05^{* *}$ \\
\hline $\begin{array}{l}\text { Share of population } \\
75+\end{array}$ & $1.31^{+}$ & $1.30^{+}$ & 1.26 & 1.26 \\
\hline Extended EU group & 0.97 & 1.23 & 1.20 & 1.21 \\
\hline GDP per capita & 1.12 & 1.19 & 1.14 & 1.14 \\
\hline Democratization & $1.17^{+}$ & $1.21^{*}$ & $1.20^{*}$ & $1.20^{*}$ \\
\hline Trade existence & & & $684,293.90^{* * *}$ & $685,783.60^{* * *}$ \\
\hline $\begin{array}{l}\text { Network exposure: } \\
\text { proximity }\end{array}$ & $111.19^{* * *}$ & $203.81^{* * *}$ & $373.76^{* * *}$ & $374.59^{* * *}$ \\
\hline $\begin{array}{l}\text { Network exposure: } \\
\text { culture }\end{array}$ & & 0.05 & 0.09 & 0.08 \\
\hline $\begin{array}{l}\text { Network exposure: } \\
\text { trade }\end{array}$ & & & 0.29 & 0.28 \\
\hline $\begin{array}{l}\text { Network exposure: } \\
\text { colonies }\end{array}$ & & & & 1.02 \\
\hline Observations & 9080 & 9080 & 9080 & 9080 \\
\hline Log Likelihood & -195.847 & -195.104 & -194.559 & -194.557 \\
\hline Akaike Inf. Crit & 407.695 & 408.208 & 411.117 & 413.115 \\
\hline
\end{tabular}

Note: ${ }^{+} p<0.1 ;{ }^{*} p<0.05 ;{ }^{* *} p<0.01 ;{ }^{* * *} p<0.001$ 
Table 6.3 Results-additive diffusion models with non-normalized colonial exposure

\begin{tabular}{|c|c|c|c|c|}
\hline & (1) & (2) & (3) & (4) \\
\hline 1945-1977 & $0.0001^{* * *}$ & $0.0000^{* * *}$ & $0.00^{* * *}$ & $0.00^{* * *}$ \\
\hline 1978-2010 & $0.0000^{* * *}$ & $0.0000^{* * *}$ & $0.00^{\star * *}$ & $0.00^{\star \star \star}$ \\
\hline $\begin{array}{l}\text { Women pol. } \\
\text { empowerment } \\
\text { index }\end{array}$ & $1.05^{* *}$ & $1.06^{* *}$ & $1.05^{* *}$ & $1.06^{* *}$ \\
\hline $\begin{array}{l}\text { Share of population } \\
75+\end{array}$ & $1.31^{+}$ & $1.30^{+}$ & 1.26 & 1.34 \\
\hline Extended EU group & 0.97 & 1.23 & 1.20 & 1.16 \\
\hline GDP per capita & 1.12 & 1.19 & 1.14 & 1.13 \\
\hline Democratization & $1.17^{+}$ & $1.21^{*}$ & $1.20^{*}$ & $1.20^{*}$ \\
\hline Trade existence & & & $684,293.90^{* * *}$ & $789,606.40^{* \star \star}$ \\
\hline $\begin{array}{l}\text { Network exposure: } \\
\text { proximity }\end{array}$ & $111.19^{* * *}$ & $203.81^{* * *}$ & $373.76^{* * *}$ & $239.64^{\star *}$ \\
\hline $\begin{array}{l}\text { Network exposure: } \\
\text { culture }\end{array}$ & & 0.05 & 0.09 & 0.07 \\
\hline $\begin{array}{l}\text { Network exposure: } \\
\text { trade }\end{array}$ & & & 0.29 & 0.29 \\
\hline $\begin{array}{l}\text { Network exposure: } \\
\text { colonies }\end{array}$ & & & & 2.02 \\
\hline Observations & 9080 & 9080 & 9080 & 9080 \\
\hline Log Likelihood & -195.847 & -195.104 & -194.559 & -194.026 \\
\hline Akaike Inf. Crit & 407.695 & 408.208 & 411.117 & 412.052 \\
\hline
\end{tabular}

Note: ${ }^{+} p<0.1 ;{ }^{*} p<0.05 ;{ }^{* *} p<0.01 ;{ }^{* * *} p<0.001$

\section{Literature}

Aiken, Leona S., and Stephen G. West. 1991. Multiple Regression: Testing and Interpreting Interactions. Thousand Oaks: Sage.

Bonoli, Giuliano. 2007. "Time Matters." Comparative Political Studies 40 (5): 495-520.

Bonoli, Giuliano, and Frank Reber. 2010. "The Political Economy of Childcare in OECD Countries: Explaining Cross-National Variation in Spending and Coverage Rates." European Journal of Political Research 49 (1): 97-118.

Campbell, John C., Naoki Ikegami, and Soonman Kwon. 2009. "Policy Learning and Cross-National Diffusion in Social Long-Term Care Insurance: Germany, Japan, and the Republic of Korea." International Social Security Review 62 (4): 63-80. 
Cerami, Alfio. 2008. "Europeanization and Social Policy in Central and Eastern Europe.” In Européanisation. D'ouest En Est. Coll. Logiques Politiques, edited by François Bafoil and Timm Beichelt, 137-168. Paris: L'Harmattan.

Colombo, Francesca, Ana Llena-Nozal, Jérôme Mercier, and Frits Tjadens. 2011. Help Wanted? Providing and Paying for Long-Term Care. Paris: OECD Publishing.

Commission of the European Communities. 1993. Social Protection in Europe. Report from the Commission C0M(93) 531 final. Last accessed January 15, 2021. http://aei.pitt.edu/42125/1/com1993_0531en01.pdf.

Companje, Karel-Peter. 2014. "Financing High Medical Risks in the Netherlands: Healthcare, Social Insurance and Political Compromises." In Financing High Medical Risks: Discussions, Developments, Problems and Solutions on the Coverage of the Risk of Long-Term Care in Norway, Germany and the Netherlands Since 1945 in European Perspective, edited by KarelPeter Companje, 101-175. History of healthcare insurance 5. Amsterdam: Amsterdam University Press.

Coppedge, Michael, John Gerring, Carl H. Knutsen, Staffan I. Lindberg, Jan Teorell, David Altman, Michael Bernhard et al. 2020. "V-Dem Codebook V10." SSRN Electronic Journal.

Council of the European Union. 1993. "Declaration of Principle of the Council of the European Union and the Ministers for Social Afffairs." Meeting with the Council. 93/C 343/01.

De Carvalho, Gabriela, and Johanna Fischer. 2020. "Healthcare and LongTerm Care Systems and Reforms-Concepts and Operationalisations for Global and Historical Comparative Research.” SFB 1342 Technical Paper Series 3. Bremen.

Elkins, Zachary, and Beth Simmons. 2005. "On Waves, Clusters, and Diffusion: A Conceptual Framework." The ANNALS of the American Academy of Political and Social Science 598 (1): 33-51.

Esquivel, Valeria. 2017. "The Rights-Based Approach to Care Policies: Latin American Experience.” International Social Security Review 70 (4): 87-103. Feng, Zhanlian. 2019. "Global Convergence: Aging and Long-Term Care Policy Challenges in the Developing World.” Journal of Aging \& Social Policy 31 (4): 291-297.

Fischer, Johanna, and Meika Sternkopf. 2021. "The Historical Long-Term Care Systems Dataset (HLTCS): Data Collection and Codebook." CRC 1342 Technical Paper Series (forthcoming). 
Guillén, Ana M., and Bruno Palier. 2004. "Introduction: Does Europe Matter? Accession to EU and Social Policy Developments in Recent and New Member States." Journal of European Social Policy 14 (3): 203-209.

Haggard, Stephan, and Robert R. Kaufman. 2009. Development, Democracy, and Welfare States. Princeton: Princeton University Press.

Hennessy, Patrick. 1994. "Who Looks After the Elderly?” OECD Observer 188 (3): 15-19. https://doi.org/10.1787/observer-v1994-3-en.

Hervey, Tamara, and Bart Vanhercke. 2010. "Health Care and the EU: The Law and Policy Patchwork." In Health Systems Governance in Europe, edited by Elias Mossialos, Govin Permanand, Rita Baeten, and Tamara K. Hervey, 84-133. Cambridge: Cambridge University Press.

Huber, Evelyne, and John D. Stephens. 2001. Development and Crisis of the Welfare State: Parties and Policies in Global Markets. Chicago, IL. University of Chicago Press.

Jensen, Carsten. 2011. "Determinants of Welfare Service Provision After the Golden Age." International Journal of Social Welfare 20 (2): 125-134.

Kuhlmann, Johanna, Delia González de Reufels, Klaus Schlichte, and Frank Nullmeier. 2020. "How Social Policy Travels: A Refined Model of Diffusion." Global Social Policy 20 (1): 80-96.

Leitner, Sigrid. 2013. Varianten von Familialismus: Eine historisch vergleichende Analyse der Kinderbetreungs- und Altenpflegepolitiken in kontinentaleuropäischen Wohlfahrtsstaaten. 1. Aufl. Sozialpolitische Schriften 91. Berlin: Duncker \& Humblot.

Lloyd-Sherlock, Peter. 2010. Population Ageing and International Development: From Generalisation to Evidence. Bristol: Policy Press.

Lührmann, Anna, Marcus Tannenberg, and Staffan I. Lindberg. 2018. "Regimes of the World (RoW): Opening New Avenues for the Comparative Study of Political Regimes." Politics and Governance 6 (1): 60-77.

Maags, Christina. 2020. "Long-Term Care Insurance Adoption in East Asia: Politics, Ideas, and Institutions." Politics \& Policy 28 (2): 1-38.

Marsh, David, and J. C. Sharman. 2009. "Policy Diffusion and Policy Transfer." Policy Studies 30 (3): 269-288.

Mattli, Walter, and Thomas Plümper. 2002. "The Demand-Side Politics of EU Enlargement: Democracy and the Application for EU Membership.” Journal of European Public Policy 9 (4): 550-574.

Matus-Lopez, Mauricio, and Camilo Cid Pedraza. 2016. "New Long-Term Care Policies in Latin America: The National System of Care in Uruguay." Journal of the American Medical Directors Association 17 (7): 663-665. 
Mossig, Ivo, Michael Windzio, Fabian Besche-Truthe, and Helen Seitzer. 2021. "Networks of Global Social Policy Diffusion: The Effects of Culture, Economy, Colonial Legacies and Geographic Proximity." In Networks and Geographies of Global Social Policy Diffusion: Culture, Economy and Colonial Legacies, edited by Michael Windzio, Ivo Mossig, Fabian Besche-Truthe, and Helen Seitzer, 1-26. Basinstoke: Palgrave Macmillan.

O'Connor, Julia S. 2005. "Policy Coordination, Social Indicators and the Social-Policy Agenda in the European Union." Journal of European Social Policy 15 (4): 345-361.

Obinger, Herbert. 2019. "Sozio-ökonomische Theorie des Wohlfahrtsstaates." In Handbuch Sozialpolitik, edited by Herbert Obinger and Manfred G. Schmidt, 97-116. Wiesbaden: Springer.

Obinger, Herbert, Carina Schmitt, and Peter Starke. 2013. "Policy Diffusion and Policy Transfer in Comparative Welfare State Research." Social Policy \& Administration 47 (1): 111-129.

Orloff, Ann S. 2005. "Social Provisions and Regulations: Theories of the State, Social Policies and Modernity." In Remaking Modernity: Politics, History, and Sociology, edited by Julia Adams, Elisabeth S. Clemens, and Ann S. Orloff, 190-224. Politics, history, and culture. Durham: Duke University Press.

Österle, August, Lisa Mittendrein, and Katarina Meichenitsch. 2011. "Providing Care for Growing Needs: The Context for Long-Term Care in Central and South Eastern Europe." In Long-Term Care in Central and South Eastern Europe, edited by August Österle. 1st, New ed., 17-40. Frankfurt a.M: Peter Lang GmbH Internationaler Verlag der Wissenschaften.

Österle, August, and Heinz Rothgang. 2010. "Long-Term Care.” In the Oxford Handbook of the Welfare State, edited by Francis G. Castles, Stephan Leibfried, Jane Lewis, Herbert Obinger, and Christopher Pierson, 378-390. Oxford: Oxford University Press.

Pacolet, Jozef, Ria Bouten, Hilde Hilde Lanoye, and Katia Versieck. 1999. Social Protection for Dependency in Old Age in the 15 EU Member States and Norway: Synthesis Report Commissioned by the European Commission and the Belgian Minister of Social Affairs. Social security and social integration. Luxembourg: Office for Official Publications of the European Communities.

Peng, Ito. 2005. "The New Politics of the Welfare State in a Developmental Context: Explaining the 1990s Social Care Expansion in Japan." In Transforming the Developmental Welfare State in East Asia, edited by Huck-ju Kwŏn, 73-97. Social policy in a development context. Basingstoke, Hampshire [u.a.]: Palgrave Macmillan. 
Pfau-Effinger, Birgit. 2005. "Welfare State Policies and the Development of Care Arrangements." European Societies 7 (2): 321-347.

Pfau-Effinger, Birgit. 2019. "Kulturelle Ideen als Grundlage der Wohlfahrtsstaatsforschung." In Obinger and Schmidt 2019, 217-234.

Pierson, Paul. 1996. "The New Politics of Th Welfare State." World Politics 48 (2): 143-173.

Ranci, Costanzo, and Emmanuele Pavolini. 2015. "Not All That Glitters Is Gold: Long-Term Care Reforms in the Last Two Decades in Europe." Journal of European Social Policy 25 (3): 270-285.

Scheil-Adlung, Xenia. 2015. "Long-Term Care Protection for Older Persons: A Review of Coverage Deficits in 46 Countries." Extension of Social Security series 50. Unpublished manuscript. Last accessed August 1, 2018. www.ilo.org/wcmsp5/groups/public/---ed_protect/---soc_sec/docume nts/publication/wcms_407620.pdf.

Schmidt, Hillel. 2005. "The Israeli Long-term Care Insurance Law: Selected Issues in Providing Home Care Services to the Frail Elderly." Health \& Social Care in the Community 13 (3): 191-200.

Schmidt, Manfred G. 2019. "Sozialpolitik in Demokratien und Autokratien." In Handbuch Sozialpolitik, edited by Herbert Obinger and Manfred G. Schmidt, 235-254. Wiesbaden: Springer Fachmedien Wiesbaden.

Schmitt, Carina. 2015. "Social Security Development and the Colonial Legacy.” World Development 70: 332-342.

Schmitt, Carina, Hanna Lierse, Herbert Obinger, and Laura Seelkopf. 2015. "The Global Emergence of Social Protection." Politics \& Society 43 (4): 503 524.

Schmitt, Carina, and Herbert Obinger. 2013. "Spatial Interdependencies and Welfare State Generosity in Western Democracies, 1960-2000.” Journal of European Social Policy 23 (2): 119-133.

Second World Assembly on Ageing. 2002. "Political Declaration and Madrid International Plan of Action on Ageing: Second World Assembly on Ageing, Madrid, Spain, 8-12 April 2002." Unpublished manuscript. Last accessed August 15, 2018. http://www.un.org/en/events/pastevents/pdfs/ Madrid_plan.pdf.

Sipilä, Jorma, Margit Andersson, Sten-Erik Hammarqvist, lars Nordlander, Pirkko-Liisa rauhala, Kare Thomsen, and Hanne Warming Nielsen. 2000. "A Multiture of Universal Public Services-How and Why Did Four Scandinavian Countries Get Their Social Care Service Model?" In Social Care Services: The Key to the Scandinavian Welfare Model, edited by Jorma Sipilä. Repr, 27-50. Aldershot: Ashgate. 
Sundström, Aksel, Pamela Paxton, Yi-ting Wang, and Staffan I. Lindberg. 2015. "Women's Political Empowerment: A New Global Index, 19002012.” SSRN Electronic Journal.

Theobald, Hildegard, and Kristine Kern. 2011. "The Introduction of LongTerm Care Policy Schemes: Policy Development, Policy Transfer and Policy Change." Policy \& Politics 39 (3): 325-342.

United Nations Department of Economic and Social Affairs. 2016. "Briefing Paper: Growing Need for Long-Term Care: Assumptions and Realities." Last accessed October 6, 2018. https://www.un.org/esa/socdev/ageing/doc uments/un-ageing_briefing-paper_Long-term-care.pdf.

United Nations Department of Economics and Social Affairs Population Division. 2019. "World Population Prospects 2019: File POP/9-1: Percentage Total Population (Both Sexes Combined) By Broad Age Group, Region, Subregion and Country, 1950-2100.” POP/DB/WPP/Rev.2019/POP/F091. Last accessed August 27, 2019. https://population.un.org/wpp/ Download/Files/1_Indicators\%20(Standard)/EXCEL_FILES/1_Populat ion/WPP2019_POP_F09_1_PERCENTAGE_OF_TOTAL_POPULA TION_BY_BROAD_AGE_GROUP_BOTH_SEXES.xlsx.

Valente, Thomas Q. 1995. "Network Models of the Diffusion of Innovations." New Jersey: Hampton.

Valente, Thomas W. 2005. "Network Models and Methods for Studying the Diffusion of Innovations." In Models and Methods in Social Network Analysis, edited by Peter J. Carrington, John Scott, and Stanley Wasserman. 1st ed., 98-116. Cambridge University Press.

Windzio, Michael. 2013. Regressionsmodelle für Zustände und Ereignisse: Eine Einführung. Wiesbaden: Springer.

World Health Organization. 2015. World Report on Ageing and Health. Geneva: World Health Organization. Last accessed August 10, 2018. http://apps. who.int/iris/bitstream/10665/186463/1/9789240694811_eng.pdf.

World Health Organization. 2017. Towards Long-Term Care Systems in SubSaharan Africa. WHO series on long-term care. Geneva: World Health Organization. Last accessed August 8, 2018. http://www.who.int/ageing/ publications/ltc-series-subsaharan-africa/en/.

Zeileis, Achim, Susanne Köll, and Nathaniel Graham. 2020. "Various Versatile Variances: An Object-Oriented Implementation of Clustered Covariances in R.” Journal of Statistical Software 95 (1): 1-36. 
Open Access This chapter is licensed under the terms of the Creative Commons Attribution 4.0 International License (http://creativecommons.org/ licenses/by/4.0/), which permits use, sharing, adaptation, distribution and reproduction in any medium or format, as long as you give appropriate credit to the original author(s) and the source, provide a link to the Creative Commons license and indicate if changes were made.

The images or other third party material in this chapter are included in the chapter's Creative Commons license, unless indicated otherwise in a credit line to the material. If material is not included in the chapter's Creative Commons license and your intended use is not permitted by statutory regulation or exceeds the permitted use, you will need to obtain permission directly from the copyright holder.

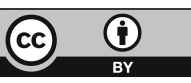

